\title{
Professional Behavior In Physical Therapist Educational Programs: Perspectives of Selected Senior Faculty
}

\section{Tamara L. Phelan}

Thomas J. Long School of Pharmacy and Health Sciences, tphelan@pacific.edu

Follow this and additional works at: https://nsuworks.nova.edu/ijahsp

Part of the Medicine and Health Sciences Commons

\section{Recommended Citation}

Phelan TL. Professional Behavior In Physical Therapist Educational Programs: Perspectives of Selected Senior Faculty. The Internet Journal of Allied Health Sciences and Practice. 2014 Apr 01;12(2), Article 8.

This Manuscript is brought to you for free and open access by the College of Health Care Sciences at NSUWorks. It has been accepted for inclusion in Internet Journal of Allied Health Sciences and Practice by an authorized editor of NSUWorks. For more information, please contact nsuworks@nova.edu. 


\title{
Professional Behavior In Physical Therapist Educational Programs: Perspectives of Selected Senior Faculty
}

\begin{abstract}
Purpose: The purpose of this study was to analyze how selected senior instructors in physical therapist educational programs define and seek to impart information on professional behavior. Methods: A qualitative case study approach was used to gather data from eight instructors teaching in four physical therapist educational programs in a selected region. Each interview was analyzed as an individual case study, followed by a cross case analysis to identify common themes. Results: Interpretational analysis using a process of constant comparison revealed nine common themes: 1) Instructors found it difficult to broadly define professional behavior. 2) Instructors expect students to be on time. 3) Instructors expect students to speak and act with courtesy and respect. 4) Instructors expect students to communicate appropriately. 5) Instructors expect students to dress appropriately. 6) Instructors expect students to participate in class. 7) Instructors consciously model professional behavior as a way to communicate their expectations. 8) Instructors give instructions and provide students with feedback about professional behavior. 9) Instructors do not attach a specific grade to professional behavior. Conclusions: Although instructors indicated a lack of confidence in consistency regarding professional behavior expectations, the themes that emerged in this study fit within existing descriptions of professional behavior for clinical physical therapists. Instructor perceptions of strategies for conveying information about professional behavior to students were consistent with existing literature on modeling and explicit teaching. .
\end{abstract}

\section{Author Bio(s)}

Tamara L. Phelan, PT, EdD, is an Associate Professor, Department of Physical Therapy, Thomas J. Long School of Pharmacy and Health Sciences, Stockton California. 


\title{
TIAHSP \\ The Internet Joutnal of Allied Health Sciences and Practice \\ Dedicated to allied health professional practice and education \\ http://ijahsp.nova.edu Vol. 12 No. 2 ISSN 1540-580X \\ Professional Behavior In Physical Therapist Educational Programs: Perspectives of Selected Senior Faculty
}

\author{
Tamara L. Phelan, PT, EdD \\ Associate Professor, Department of Physical Therapy \\ Thomas J. Long School of Pharmacy and Health Sciences, Stockton California
}

United States

\begin{abstract}
Purpose: The purpose of this study was to analyze how selected senior instructors in physical therapist educational programs define and seek to impart information on professional behavior. Methods: A qualitative case study approach was used to gather data from eight instructors teaching in four physical therapist educational programs in a selected region. Each interview was analyzed as an individual case study, followed by a cross case analysis to identify common themes. Results: Interpretational analysis using a process of constant comparison revealed nine common themes: 1) Instructors found it difficult to broadly define professional behavior. 2) Instructors expect students to be on time. 3) Instructors expect students to speak and act with courtesy and respect. 4) Instructors expect students to communicate appropriately. 5) Instructors expect students to dress appropriately. 6) Instructors expect students to participate in class. 7) Instructors consciously model professional behavior as a way to communicate their expectations. 8) Instructors give instructions and provide students with feedback about professional behavior. 9) Instructors do not attach a specific grade to professional behavior. Conclusions: Although instructors indicated a lack of confidence in consistency regarding professional behavior expectations, the themes that emerged in this study fit within existing descriptions of professional behavior for clinical physical therapists. Instructor perceptions of strategies for conveying information about professional behavior to students were consistent with existing literature on modeling and explicit teaching.
\end{abstract}

\section{INTRODUCTION}

As allied health professionals, physical therapists practice in a broad range of settings including but not limited to hospitals, outpatient clinics, schools, athletic facilities, and rehabilitation centers. ${ }^{1}$ The practice environment for physical therapists has become increasingly autonomous, and in many countries, health care systems allow patients/clients direct access to the services of a physical therapist without the requirement of a third party referral. ${ }^{2,3}$ Recent work by Bury and Stokes indicates that $58 \%$ of the member countries of the World Confederation for Physical Therapy (WCPT) report some form of direct access, also called self-referral. ${ }^{4}$ Direct access has been possible in Australia and in the US military healthcare system for over 30 years and more recently has been adopted to various degrees in the Netherlands, the United Kingdom, and many areas of Canada and nonmilitary sectors of the United States. ${ }^{4,5}$ This increasingly autonomous practice environment requires high levels of professional responsibility. There is a societal presumption that professionals of all types, including allied health care professionals, will make decisions that are good for the individual and society as a whole, even when no one is watching. ${ }^{6}$ The behaviors that lead to successful management of this implicit social contract can be referred to as "professionalism."

Professionalism is the end result of a socialization process that imparts the knowledge, values, culture, and behaviors of a particular profession. ${ }^{7}$ For allied health professionals, the process of professional education may be viewed as a form of socialization, and it is the responsibility of professional educational programs to ensure that new graduates are able to meet acceptable minimal professional standards including professional behavior. ${ }^{7}$

There is a global move to develop minimal professional standards of practice for physical therapists and many countries such as the United Kingdom, Australia, Canada (by province), and the United States have formally articulated practice standards. ${ }^{8-12}$ Professional behaviors are both implicitly and explicitly outlined in a variety of ways in these documents; however, all documents

(C) The Internet Journal of Allied Health Sciences and Practice, 2014 
describe professional behaviors in the context of the clinical environment. Research regarding the professional behavior of students is similarly focused with previous work addressing primarily the expectations and perceptions of clinical educators regarding student behavior in the clinic environment. ${ }^{13,14}$

The classroom educational setting is significantly different than the clinical educational setting, and research that takes place in the clinical setting may not translate to the classroom setting in terms of behavioral expectations and strategies for developing professional behaviors. The acquisition of knowledge, skills, and behaviors in the classroom educational setting is often divided into three dimensions according to Bloom's taxonomy: cognitive, psychomotor, and affective. ${ }^{15}$ The body of scientific knowledge needed to master the cognitive and psychomotor dimensions for a physical therapist is well defined and efficiently imparted to students through a variety of traditional teaching methods. ${ }^{16,17}$ There is little research, however, that defines and describes how the affective dimension -- the standards of behavior, values, and culture associated with the profession of physical therapy -- are defined by instructors in physical therapist educational programs and imparted by them to students. ${ }^{16}$

Inappropriate behavior in both the classroom and the clinic has been identified as a concern by physical therapy academic administrators..$^{17} \mathrm{~A}$ variety of inappropriate and unprofessional student behaviors have been reported. Cary reports aggressive confrontation of faculty by students, use of profane language, a lack of respect, and encroaching on personal space. ${ }^{18}$ Hayward et al reports incidents of students at clinical affiliations failing to show up on time, failing to follow the dress code, and making inappropriate statements to patients. ${ }^{17}$ Davis reports tardiness and lack of personal responsibility. ${ }^{19}$ These reports are of concern because there is a link between the level of professional practice and professional behavior and outstanding clinicians demonstrate highly developed professional behaviors. ${ }^{20}$ Physical therapists specifically and allied health professionals in general must demonstrate good professional behavior as well as good clinical skills for effective patient management. ${ }^{21}$

There are few existing frameworks for defining and promoting professional behavior specifically aimed at students matriculating through the didactic component of physical therapist education, and those that exist use a strategy of self-assessment. In 1995, May et al introduced an approach they called "ability-based assessment" identifying ten "Generic Abilities" considered necessary for success as a physical therapist: Commitment to learning, interpersonal skills, communication skills, effective use of time and resources, use of constructive feedback, problem solving, professionalism, responsibility, critical thinking, and stress management.22 May et al further identified behavioral levels that they categorized as beginning, developing and advanced levels of competence. These levels were intended to reflect the behaviors a physical therapist student should demonstrate in each category at the end of the first year, the second year, and upon graduation from a physical therapist educational program. The Generic Abilities were validated by Jette and Portney in 2003.23

The approach used by the Generic Abilities is one of self-assessment and reflection by the student. While this is a legitimate model of learning, it does not delineate the types of inappropriate behavior most likely to be encountered in the educational setting nor give suggestions as to how a faculty member might effectively address this behavior if student self assessment is not successful. In 2010, Hayward and Blackmer proposed a model for teaching professional behavior to physical therapist students based on the "Core Values," a description of professional behavior for physical therapists developed by the American Physical Therapy Association. ${ }^{24,25}$ While this model is specifically intended for the educational setting, as opposed to the clinical setting, like the Generic Abilities, this model also relies on self-assessment and reflection. Academic and clinical faculty continues to find it challenging to identify, evaluate, and effectively remediate inappropriate behavior. ${ }^{26,27}$ The purpose of this study was to describe how senior instructors in physical therapist educational programs define professional behavior and how they impart to students information about professional behavior in the context of teaching courses not specifically devoted to the topic of professional behavior.

\section{METHODS}

\section{Researchers Perspective}

The researcher conducted all the interviews, transcribed the recorded interviews, and analyzed the data. The research design was reviewed and data analysis was checked by an external reviewer experienced in qualitative research. The researcher is employed as a full time faculty member in a physical therapist educational program; however, during the period in which the study took place, the researcher was on leave and was not physically present at the place of employment and was not responsible for any teaching, administrative, or service activities and was not otherwise active in the academic community. The participants were known to the researcher but had no previous discussions with the researcher on the specific topic of this study prior to data collection. Nonetheless, the relationship of the researcher to the participants could have influenced the data collected.

(C) The Internet Journal of Allied Health Sciences and Practice, 2014 


\section{Participants}

Criterion sampling of experienced faculty members in physical therapist educational programs was determined to be the most logical approach for this study. ${ }^{28} \mathrm{~A}$ sample consisting of two faculty from each of four regional programs was selected based on the following criteria: Participants were employed in the region of interest, they were full time instructors in physical therapist educational programs, they had at least 10 years of full time teaching experience, and they taught at least one course during the academic year in which data was collected. Employment status and years of experience are considered private information in the region in which this study took place. As a result, participants were recruited by contacting the department chair of each program. Each department chair identified two individuals who met the criteria and were willing to participate. Instructors with greater years of experience were selected because they potentially had greater exposure over time to students, and as a result, more opportunities to develop strategies for teaching professional behavior. The sample was confined to a particular geographic region in order to minimize the potential differences in behavioral expectations as a result of regional social customs.

\section{Research Design}

This was a qualitative study using a strategy of naturalistic inquiry. As described by Patton, naturalistic inquiry takes place in a real-world setting as opposed to a laboratory or other controlled setting and does not attempt to manipulate the phenomenon of interest.29 This inquiry was conducted using a case study approach. Case study is the preferred methodology to answer "how" and "why" questions when the researcher has minimal control over events and when the focus of the research is on a phenomenon in a real-life setting..$^{30}$ This approach was particularly appropriate because this study aimed to describe how instructors define and impart information about professional behavior in a real-life setting of classroom instruction in a physical therapist educational program. Each instructor was considered an individual case.

Data were gathered for each case using a standardized open-ended interview format. ${ }^{29}$ This format was chosen because it facilitates efficiency and the identification of common themes or patterns during cross-case analysis. ${ }^{29}$ The standardized interview questions were developed according to Patton's description of a "truly open-ended question"29 After initial development, each question was reviewed to assure that it would not result in a dichotomous (yes or no) response and that it only contained a singular idea. ${ }^{29}$ The final interview protocol is included as Appendix A. Each interview was transcribed verbatim and analyzed as an individual case. The individual cases were then grouped together and a cross-case analysis was conducted to identify common themes and patterns.

Multiple forms of data allow for triangulation, which may reveal convergence or inconsistencies in the findings not otherwise appreciable. ${ }^{28} \mathrm{~A}$ syllabus from each participant for a course taught in the current academic year was gathered after the interview and reviewed to investigate the convergence of results, searching for the presence or absence of information that was consistent or inconsistent with interview data. The overall research design and the final interview protocol were reviewed by an experienced qualitative researcher prior to proceeding with the study.

\section{Data Collection Procedures}

Informed consent was obtained from all participants prior to data collection. In order to encourage candid responses to interview questions, participants were informed of the descriptive nature of the study and assured that the study was not evaluative. ${ }^{28}$ Additionally, participants were assured that data would be fastidiously reviewed in order to assure that no information would be published that would potentially identify the participant or the institution. ${ }^{28}$ Each interview was recorded in order to assure that a verbatim response was captured and also to remove the possibility of unconscious selection of data favoring bias by the interviewer. ${ }^{28,29}$ Participants were allowed to answer questions without interruption and were allowed as much time as they wished to talk on a specific topic. Syllabi were collected after the interview was completed.

\section{Data Analysis}

All recorded interview data were compiled and transcribed verbatim. The transcripts were analyzed using interpretational analysis. ${ }^{28}$ The text was broken into meaningful segments, those that contained one item of information. Segments that contained similar thoughts were grouped together to form themes. Themes were continually compared and revised in a process of constant comparison in order to define and clarify the meaning of each theme. This process was carried out twice. ${ }^{31,32}$ First, a within case analysis was conducted to provide a detailed description of each individual case and identify themes within the case. Second, a cross case analysis was conducted to identify themes that were present across all cases. Finally, syllabi were analyzed for the presence or absence of information that was relevant to the transcribed data. Data analysis was cross checked and results were confirmed by an experienced qualitative researcher. 


\section{RESULTS}

\section{Participants}

Eight participants took part in this study. Participants were between the ages of 42 and 55 years old. Participants' teaching experience ranged from 11 years of full-time instruction to 25 years of full-time instruction. Five of the participants were male and three were female. All of the participants were educated at the doctoral level, 8 participants with a PhD and 2 participants with a DPT (Doctor of Physical Therapy). Two of the programs were located in private, not-for-profit institutions, and two programs were located in public institutions. The institutions were divided evenly between urban and rural communities.

\section{Themes}

Nine common themes were identified: 1) Instructors thought it was hard to define professional behavior. 2) Student professional behavior includes being on time. 3) Student professional behavior includes speaking and acting with courteousness and respect. 4) Student professional behavior includes communicating appropriately. 5) Student professional behavior includes dressing appropriately. 6) Student professional behavior includes participating in class. 7) Instructors attempt to convey professional behavior to students by conscious modeling. 8) Instructors attempt to convey professional behavior to students by making expectations clear and giving feedback. 9) Instructors do not give students a grade in professional behavior as part of their courses.

\section{Professional Behavior is Hard to Define}

Although no clear theme emerged relative to the actual definition of professional behavior, seven of eight participants found the notion of defining professional behavior difficult. One instructor commented "goodness gracious that's a hard one, can we stop that (the recorder) while I think?" Other comments were "that's a tough one" and "it's really a good question" and "tt's really hard for me to put my finger on that." Several instructors noted that they really hadn't given it much thought, while others simply fell silent when the question was asked.

\section{Being On Time}

Instructors without exception identified that professional behavior includes being on time to class. Being on time was described as mundane; however, "if that's missing, you are not professional." Several instructors noted that if a student was late, and they knew they were going to be late, they expected them to call and make this known to the instructor. When asked to describe a student who exceeds their expectations in terms of professional behavior, several instructors described this student as always on time. Conversely a student who was not meeting expectations in terms of professional behavior was described as always late.

\section{Courtesy and Respect}

Without exception, instructors identified that professional behavior includes being courteous and respectful in actions and interactions. Most instructors stated overtly that they expected students to be respectful and courteous, saying that they expect students to demonstrate "respect" and a "high level of courtesy" and that "being rude" is unacceptable. Instructors described a wide range of disrespectful behaviors; one instructor gave the example of inappropriate jokes in the gross anatomy lab saying, "I don't think any of these people donated their bodies to science so that people could make jokes about them." Other examples were "blurting something out in class that's not respectful" and "something that's really tacky said inappropriately" and "gossip about another instructor, another student, just saying things that would be incredibly divisive [and] in an inappropriate forum." Many more clear cut examples of disrespectful behavior were given such as sleeping in class, talking among themselves while the instructor is lecturing, passing notes, texting while in class, and surfing the internet while in class.

\section{Appropriate Communication}

A majority of the instructors interviewed stated overtly that professional behavior includes being skillful communicators and communicating appropriately. Instructors expected students to have "good communication skills" to "take responsibility for communicating well" and to use a "more formal" communication style. Instructors acknowledged that appropriate communication is setting-dependent and they expected students to be able to recognize this. Knowing when it was safe to "vent" or complain versus when it was inappropriate was listed as an important characteristic. Foul language or colloquialisms were additional examples of unacceptable communication. One instructor noted that communication has a clinical connection saying, "if you are talking about politics to your patients...and your patient is conservative or quite religious, you know it can interfere with your ability to deliver appropriate physical therapy."

\section{Appropriate Attire}

All but one instructor identified dressing appropriately as an important professional behavior. One instructor defined appropriate dress as "basically conservative, that you should dress conservatively because we are working with people from a lot of different countries, different backgrounds..." Dressing appropriately was described as "very basic," but "if that's missing, you are not

(C) The Internet Journal of Allied Health Sciences and Practice, 2014 
professional." Several instructors alluded to the fact that they expect students to recognize that the standard of dress is different when they will be seen by professionals outside the program saying, "when we have a guest speaker they dress appropriately." Appropriate attire was not always stated overtly by instructors as an expectation, but came to light when discussing other topics; for example, when discussing modeling one instructor stated "If you want your students to dress at a certain level when a guest is in, you can't come in dressed otherwise."

\section{Participation}

Half of the participants in this study articulated an expectation that students participate in class noting that "to exhibit professional behavior, a student needs to participate in the classroom experience, which means that the student needs to talk in small group discussions and when they are asked questions, they need to respond in a thoughtful manner" and "when they are part of a group, pull their weight." One instructor described an unprofessional student as one who does not participate in class.

\section{Conscious Modeling}

All but one instructor indicated that they consciously model professional behavior as a way to convey information about appropriate professional behavior. For example, "I guess if I think about this the way you do it more than anything is by example" and "Well, I guess we all try and model professional behavior, and "I know that I try and do that" and "this is nothing new, but you've got to model it." Instructors hoped to model behavior consistent with what they expected from their students. For example, "You're asking your students to be on time for an outside lab, you can't be late. You're having a bad day; your students shouldn't know one way or the other." Instructors saw modeling as an effective tool noting "It really is amazing how students kind of mimic your behavior" and "you know the faculty performing professional behaviors that the students become proud of and may possibly want to emulate to some degree is really helpful." Several instructors commented that they felt that there is room for faculty improvement in this area, "As a profession, we have to model professionalism, and I am not thinking of anyone specifically, but over the years I have cringed on several occasions when the [inappropriate] behaviors of colleagues in the classroom became apparent."

\section{Clear Expectations and Feedback}

All Instructors stated that they attempt to convey information about appropriate professional behavior to students by making their expectations clear and giving feedback to students about their behavior. Most instructors cited their syllabus as one way that they made their expectations clear. Additionally, they described many instances of giving both general and specific information about their expectations; for example, "When I send them out on observations I say "make sure you call the day before so everybody knows that you are expected and talk to your clinical instructor prior to showing up'."

Instructors cited a variety of ways that they give feedback including reprimanding the student at the time the behavior occurs, pulling the student aside later and providing feedback privately, and verbal and non-verbal cues. Some instructors indicated that over the years they have changed saying, "much more I will confront a student in direct ways where as in the past I probably would not" and "...part of my role as an educator is to let students know when they're not doing well and that includes on the interpersonal professional side, even though it's not in the syllabus."

\section{Professional Behavior is Not Graded}

All but two instructors did not assign a specific component of the grade for their course to professional behavior. Several instructors indicated that they were uncomfortable with the notion of grading professional behavior because they thought it was too subjective, saying, "one person interprets what is unprofessional when another doesn't." and "I think the problem is trying to measure it." Most instructors noted that professional behavior was handled for better or for worse at the department level as opposed to the individual course level, although they did not always think this was satisfactory. For example, "you have to, in essence, call a major foul and bring somebody in, [which] really makes it [the inappropriate behavior] a high level before that [the consequence] is triggered." Several instructors felt they captured some component of professional behavior by giving points for things such as participation and grading students down on assignments when they were not turned in on time. The two instructors who did grade professional behavior did this by giving a pre-determined amount of points at the beginning of the semester and then taking off points if unprofessional behavior occurred.

\section{Document Review}

Syllabi analysis revealed that all syllabi contained a statement regarding academic integrity, and all but one contained a general statement somewhere in the document that students would be expected to behave professionally in the course. Three of these general references referred students to the student handbook, institutional policy and procedures, or the Generic Abilities for a more detailed description of professional behavior.

(c) The Internet Journal of Allied Health Sciences and Practice, 2014 
The majority of the syllabi did not specifically address the behavioral themes that emerged during interviews with the participants. While four syllabi gave detailed information about attendance expectations, only two syllabi specifically stated that students were expected to be on time. These same two syllabi also specifically mentioned that students were expected to show respect, and that they were expected to participate fully in class. Additionally, one syllabus noted that students were expected to communicate appropriately, and one syllabus noted that students were expected to dress appropriately. Two syllabi included course objectives specifically identified as related to professional behavior, and only one syllabus associated a component of the grade with professional behavior. In this instance, the syllabi clearly stated that a student who did not meet professional behavior expectations would fail the course. Three syllabi that did not specifically include a professional behavior grade did include class participation grades.

\section{DISCUSSION}

The classroom setting for allied health professional educational programs, and for physical therapist educational programs specifically, is more structured than a clinical setting. As a result, the formal academic component of training provides an excellent venue for teaching professional behavior and for remediation of unacceptable professional behavior. The mean length in weeks of academic instruction in physical therapist educational programs in the United States was 85.4 weeks for the academic year 2011 to $2012 .{ }^{33}$ In contrast, the mean length in weeks of full-time clinical education in those same programs during the same time was 35.9 weeks. ${ }^{33}$ On average, there is almost two and a half times the hours of classroom instruction when compared to clinical instruction, and this substantial opportunity to influence the behavior of students should not be overlooked.

\section{Lack of Clarity and Confidence Regarding Professional Behavior Standards}

Despite the acknowledged interest in professionalism among allied health practitioners and the substantial teaching opportunity that the classroom represents, participants in this study still considered it hard to define professional behavior and were also reluctant to grade professional behavior. Wolf-Burke et al proposed that faculty do not assess professional behavior because they believe that the behavior is someone else's problem, they lack confidence in the accuracy of the observed behavior, and they perceive a lack of support from the institution. ${ }^{26}$ The results of this study add legitimacy to this proposal. Several participants in this study expressed directly that they felt uncomfortable judging what was acceptable professional behavior noting, "I think the problem is trying to measure it" and "how do you quantify it, you know? How many points do you take off for what behavior? It's...very subjective in nature." While participants in this study did not overtly state that they felt that professional behavior was someone else's problem, they did express a lack of clarity as to who ultimately should deal with unacceptable professional behavior in the classroom when their initial efforts at remediation failed. Although participants in this study did not overtly state that they perceived a lack of support from the institution, they expressed the notion that systems in place did not always meet their needs in terms of responding to behavioral issues. It is notable that instructors expressed these reservations even though there are frameworks available that were developed expressly for the purpose of defining and assessing professional behavior in physical therapist educational programs. This suggests that current models may not be easily applicable to students in the educational setting when attempting to evaluate what is appropriate on a daily basis for students in a classroom setting.

The lack of confidence in the consistency of professional behavior expectations among faculty may not be warranted. The themes identified in this study were consistent with behaviors described in five of the seven APTA Core Values, the existing description of professional behavior for physical therapists in the United States. ${ }^{26}$ Additionally, the results of this study are consistent with previous work. In a survey of physical therapy educators, Davis reported concerns about tardiness, violation of dress code, and disrespect for others. ${ }^{19}$ These concerns are consistent with three of the themes identified in this study: being on time, dressing appropriately, and interacting with courtesy and respect. More recent work by Chipchase et al sought to identify characteristics that indicated a student was well prepared for clinical learning. ${ }^{13}$ Although this study involved the perceptions of clinical educators, it has particular relevance to this project because the clinical educators described characteristics that students should demonstrate at the beginning of the clinical learning experience; in other words, the characteristics that students should have developed during the didactic portion of their education. Among the themes identified in this study, three were considered more important than others: willingness, professionalism, and personal attributes. ${ }^{13}$ Two characteristics within these themes, willingness to participate in learning and appropriate dress, are consistent with two themes identified in this study, appropriate attire and participation. ${ }^{13}$

\section{Modeling and feedback}

Participants in this study identified two main methods that they use in the classroom to convey information about professional behavior. First, they consciously model the behavior they expect from students. Wolff-Burke et al suggest that role modeling is so important that faculty who are unwilling to model appropriate behavior should not be teaching students in physical therapy educational programs. ${ }^{26}$ Wolf-Burke et al. further suggests that failure to consciously role model appropriate professional

(c) The Internet Journal of Allied Health Sciences and Practice, 2014 
behavior represents a potentially important lost opportunity to teach students about professional behavior using a process that has been described as transcending lecture. ${ }^{26}$ Bringing to light the importance of role modeling and consciously assessing and employing this potentially powerful tool to improve professional behavior performance could have important positive consequences for educators and professionals.

Second, participants reported that they give students information about their expectations followed by feedback on student performance when necessary. This description is consistent with explicit teaching. ${ }^{20}$ Explicit teaching is characterized as communicating expectations and giving constructive criticism to students about professional behaviors. ${ }^{20}$ Although participants in this study indicated that they give feedback, they were not always specific about when that feedback occurred. Feedback about professional behaviors must be immediate. Silence when unprofessional behavior occurs sends a strong message of acceptance that cannot be overcome no matter how detailed a description of acceptable behavior exists on paper. ${ }^{26}$ The absence of feedback in the face of unacceptable behavior has been described as fairly commonplace in educational settings. Ignoring this behavior in the educational setting is not without consequence and may contribute to later difficulties for students. ${ }^{34}$

\section{Incremental consequences}

No examples of incremental consequences for unacceptable professional behavior were identified in this study. While almost every course syllabus reviewed in this study contained a statement requiring that students behave professionally, clear information about the consequences of inadequate professional behavior was notably absent. Conversely, information on academic performance was covered in significant detail. Participants in this study indicated that they are not always sure what to do with students who do not respond to their classroom interventions for unacceptable professional behavior when the only formal process available involved inappropriately serious consequences, such as dismissal. Giving feedback at the classroom level when unacceptable behavior occurs and imposing consequences incrementally, as opposed to reserving consequences for particularly grievous breaches of behavior, ensures that students are treated fairly and gives them an opportunity to improve prior to the implementation of serious consequences.

\section{LIMITATIONS}

While the method of recruitment used in this study allowed participants to maintain a certain degree of privacy regarding their participation and may have fostered candid expression, it confined data collection to the actual participants. No data were collected regarding the number of qualified subjects who did not participate. Additionally, the majority of the participants in this study were between 50 and 55 years of age, representing only one generation. The attitudes and expectations of this generation with respect to professional behavior standards may not be representative of younger generations.

\section{CONCLUSION}

Participants in this study recognized that professional behavior in the classroom is important and that inappropriate behavior in the classroom is difficult to address. A lack of consistency regarding professional behavior expectations emerged as a concern; however, the themes that emerged in this study are consistent with existing descriptions of professional behavior, and these concerns may be unwarranted. Modeling and explicit teaching emerged as the two strategies used by participants for conveying information about professional behavior. The clinical setting and the classroom setting are very different, and there is a need for investigations that address professional behavior specifically in the classroom. Equally valuable would be research that proposes and investigates the effectiveness of models for addressing professional behavior in the classroom other than self-assessment and reflection. Finally, it would be useful to investigate whether increased awareness of existing descriptions of professional behavior that are consistent with faculty perceptions might increase the ability of faculty to address professional behavior in the classroom setting.

\section{REFERENCES}

1. Guide to Physical Therapist Practice. Revised 2nd ed. Alexandria, VA: American Physical Therapy Association; 2003:31.

2. WCPT Keynotes: Direct Access and Patient Self-referral. World Confederation for Physical Therapy web site. http://www.wcpt.org/sites/wcpt.org/files/files/Keynote_DirectAccess.pdf. Accessed 07/21/2013

3. WCPT Policy Statement: Direct Access and patient/client self-referral to physical therapy. World Confederation for Physical Therapy web site. http://www.wcpt.org/policy/ps-direct-access. Accessed 7/21/2013

4. Bury TJ, Stokes EK. A global view of direct access and patient self-referral to physical therapy: implications for the profession. Phys Ther. 2013;93(4):449-59. [PMID 23197847]

5. FAQ: Direct Access at the State Level. American Physical Therapy Association web site. http://www.apta.org/Statelssues/DirectAccess/FAQs/ Accessed May 22, 2013.

6. Weidman JC, Twale DJ, Stein EL. Socialization of graduate and professional students in higher education, a perilous passage? San Francisco, CA: Jossey-Bass Publishers; 2001.

(c) The Internet Journal of Allied Health Sciences and Practice, 2014 
7. Swisher LL, Beckstead JW, Bebeau MJ. Factor analysis as a tool for survey analysis using a professional role orientation inventory as an example. Phys Ther. 2004;84(9):784-99. [PMID 15330692]

8. WCPT Policy statement: Standards of physical therapist practice. World Confederation for Physical Therapy web site. http://www.wcpt.org/policy/ps-standards Accessed 7/22/2013.

9. Australian Standards for Physiotherapy. Australian Physiotherapy Council website. http://www.physiocouncil.com.au/files/the-australian-standards-for-physiotherapy. Accessed 7/22/2013

10. Nova Scotia Standards of Physiotherapy Practice. The Nova Scotia College of Physiotherapists web site. http://nsphysio.com/resources/Practice+Standards+for+Physiotherapists+2008.pdf Accessed 7/22/2013.

11. Standards of Practice for Alberta Physiotherapists. Physiotherapy Alberta web site. http://www.physiotherapyalberta.ca/files/practice_standards_all_2012 revised.pdf. Accessed 7/22/2013

12. American Physical Therapy Association Professionalism in Physical Therapy: Core Values. American Physical Therapy web site. http://www.physiotherapyalberta.ca/files/practice_standards_all_2012_revised.pdf. Accessed 7/22/2013

13. Chipchase LS, Buttrum PJ, Dunwoodie R, Hill AE, Mandrusiak A, Moran M. Characteristics of student preparedeness for clinical learning: clinical educator perspectives using the delphi approach. BMC Medical Education. 2012;12:112. doi: 10.1186/1472-6920-12-112. [PMID: 23145840]

14. Cross V. The Same But Different A Delphi study of clinicians' and academics' perceptions of physiotherapy undergraduates. Physiotherapy. 1999;85(1):28-39.

15. Anderson LW, Krathwohl DR, Bloom BS. A Taxonomy for Learning, Teaching and Assessing: A Revision of Bloom's Taxonomy of Educational Objectives, Complete. Reading, MA: Addison Wesley; 2001.

16. Kirk LM. Professionalism in medicine. Definitions and considerations for teaching. Proceedings of Baylor University Medical Center. 2007;20(1):13-6. [PMID 17256035]

17. Hayward L, Noonan A, Shain D. Qualitative case study of physical therapist students' attitudes, motivations, and affective behaviors. Journal of Allied Health. 1999;28(3):155-64. [PMID 10507499]

18. Cary JR. Erosion of professional behaviors in physical therapist students. Journal of Physical Therapy Education. 2001;15(3):27-34.

19. Davis DS. Teaching professionalism: a survey of physical therapy educators. Journal of Allied Health. 2009;38(2):74-80. [PMID 19623788]

20. MacDonald C, Cox P, Bartlett D, Houghton P. Consensus on methods to foster physical therapy behaviors. Journal of Physical Therapy Education. 2002;16(1):27-36.

21. Masin HL. Education in the affective domain: a method/model for teaching professional behaviors in the classroom and during advisory sessions. Journal of Physical Therapy Education. 2002;16(1):74-86.

22. May WW, Morgan BJ, Lemke JC, Karst GM, Stone HL. Model for ability-based assessment in physical therapy education. J Phys Ther Educ. 1995;9(1):3-6.

23. Jette DU, Portney LG. Construct validation of a model for professional behavior in physical therapist students. Phys Ther. 2003;83(5):432-43. [PMID 12718709]

24. Hayward LM, Blackmer B. A model for teaching and assessing core values development in doctor of physical therapy students. Journal of Physical Therapy Education. 2010;24(3):16-26.

25. American Physical Therapy Association. Professionalism in physical therapy: Core Values. Alexandria, VA: American Physical Therapy Association; 2003. www.apta.org

26. Wolff-Burke M, Ingram D, Lewis K, Odom C, Shoaf L. Generic inabilities and the use of a decision-making rubric for addressing deficits in professional behavior. Journal of Physical Therapy Education. 2007;21(3):13-22.

27. Freeman $\mathrm{J}$, Rogers $\mathrm{JL}$. A comparison of rank ordered professional attributes by clinical supervisors and allied health students. The Internet Journal of Allied Health Sciences and Practice. 2010;8(3).

28. Gall MD, Gall JP, Borg WR. Educational research: An introduction. $7^{\text {th }}$ ed. San Francisco, CA: Pearson Education, Inc. 2003.

29. Patton MQ. Qualitative research \& evaluation methods. 3rd ed. Thousand Oaks, CA: Sage Publications, Inc. 2002.

30. Yin RK. Case study research design and methods. Thousand Oaks, CA: Sage Publications. 2003.

31. Cresswell JW. Qualitative inquiry and research design: choosing among five traditions. Thousand Oaks, CA: Sage Publications Inc. 1998.

32. Strauss A, Corbin J. Basics of Qualitative Research: Grounded Theory Procedures and Techniques. Thousand Oaks, CA: Sage Publications. 1990.

33. CAPTE 2011-2012 Fact Sheet Physical Therapist Education Programs. Commission on Accreditation of Physical Therapist Education web site. http://www.capteonline.org/uploadedFiles/CAPTEorg/About_CAPTE/Resources/Aggregate_Program_Data/AggregateProgr amData PTPrograms.pdf. Accessed May 22, 2013.

(c) The Internet Journal of Allied Health Sciences and Practice, 2014 
34. Hayes KW. Pauline Cerasoli lecture: rhetoric and responsibility in physical therapy education. Journal of Physical Therapy Education. 2010;24(3):3-9. 


\section{APPENDIX A}

1. How do you define professional behavior?

2. What are your expectations of students in terms of professional behavior?

3. Can you give some examples of student behaviors that would not meet your expectations in terms of professional behavior?

4. Can you give some examples of student behaviors that would meet or exceed your expectations in terms of professional behavior?

5. What are your suggestions or thoughts about teaching professional behavior?

6 . What are your thoughts about assessing professional behavior?

7. How does student performance in the area of professional behavior affect a student in your course?

8. Is there anything else that you would like to comment about? 